\title{
CARACTERIZAÇÃO FÍSICO-QUÍMICA E MICROBIOLÓGICA DO LEITE 'IN NATURA' COMERCIALIZADO INFORMALMENTE NO MUNICÍPIO DE GARANHUNS - PE
}

\section{PHYSICAL-CHEMICAL AND MICROBIOLOGICAL CHARACTERIZATION OF THE MILK 'IN NATURE’ FROM INFORMAL COMMERCE IN THE CITY OF GARANHUNS - PE}

\author{
João R de Freitas Filho ${ }^{1}$, João S de Souza Filho ${ }^{2}$, Tiago M. Gonçalves ${ }^{3}$, José Johnathan F. de Souza ${ }^{3}$, \\ Adriano H. Izidoro da Silva ${ }^{3}$, Heraldo B de Oliveira ${ }^{4}$, Janieire D Cordeiro Bezerra ${ }^{4}$. \\ ${ }^{1}$ Professor Adjunto da Unidade Acadêmica de Garanhuns - UFRPE joaoveronice@yahoo.com.br \\ ${ }^{2}$ Técnico em Química da Unidade Acadêmica de Garanhuns- UFRPE \\ ${ }^{3}$ Estudantes do Ensino Médio da Escola Dom João da Mata Amaral - Garanhuns \\ ${ }^{4}$ Estudantes do Curso de Zootecnia da Unidade Acadêmica de Garanhuns- UFRPE
}

\section{Resumo}

O objetivo do trabalho foi avaliar as características físico-químicas e microbiológicas do leite "in natura” comercializado informalmente na cidade de Garanhuns - PE. As amostras foram coletadas em pequeno supermercado de Garanhuns - PE, entre os meses de fevereiro a junho de 2009. Os valores médios de densidade apresentaram-se abaixo e acima dos limites recomendados, respectivamente. Em relação à acidez titulável, algumas amostras apresentaram-se dentro de padrões exigidos e $40 \%$ apresentaram valores inferiores aos mínimos exigidos, e quatro amostras (26,7\%) eram de péssima qualidade microbiológica, segundo os testes de redutase. Quanto à presença dos conservantes cloro e água oxigenada, $13 \%$ e $20 \%$, respectivamente, das amostras apresentaram resultados positivos.

Palavras-chave: Leite “in natura”, parâmetros físico-químico, microbiológica.

\section{Introdução}

O leite é considerado um dos alimentos mais completos em termos nutricionais e fundamentais para dieta humana, e se constitui um excelente substrato para o desenvolvimento de uma grande diversidade de microrganismos, inclusive os patogênicos. Daí a qualidade do leite ser uma constante preocupação para técnicos e autoridades ligadas à área de saúde, principalmente pelo risco de veiculação de microrganismos relacionados com surtos de doenças de origem alimentar (LEITE et al., 2000; TIMM., 2003). 
A qualidade físico-química visa avaliar o valor alimentar ou rendimento industrial e ainda detectar possíveis fraudes. A qualidade do leite depende de programas específicos que contemplem os diversos fatores que podem influenciar na composição físico-química, microbiológica e celular. Daí, a maior parte dos países tem buscado executar programas de pagamento por qualidade, baseando-se no nível de contaminação microbiana, teores de gordura, de sólidos não gordurosos, presença de inibidores e outros parâmetros (MENDONÇA et al., 2001).

Como fonte de proteínas, gorduras, carboidratos, minerais e vitaminas, o leite torna-se também um excelente meio para o crescimento de vários grupos de microrganismos desejáveis e indesejáveis (SOUZA et al., 1995). A presença e multiplicação de microrganismos provocam alterações físico-químicas no leite, o que limita sua durabilidade.

O leite oriundo de diferentes animais, dentro de um mesmo rebanho leiteiro, apresentará, em contrapartida, variação em seus parâmetros físico-químicos, embora a mistura final do produto, a ser entregue à indústria, prioritariamente, apresente valores bastante próximos aos estabelecidos, quando se toma por base, a média nacional. Além da individualidade, diversos fatores podem ocasionar variações na composição do leite, como espécie, raça, alimentação entre outros (SÁ, 2004).

A análise da composição físico-química do leite é importante, pois também é considerada, junto às analises microbiológicas, parâmetros de qualidade do leite, possibilitando estabelecer, dessa forma um critério de pagamento ao produtor (TEIXEIRA,1998).

No Brasil, práticas inadequadas de produção e manuseio do leite nas propriedades, elevada temperatura ambiente, enorme distância entre a propriedade e o local de processamento, entre outras, tornam o leite de baixa qualidade (ROSSI, 1992). O sistema ideal de conservação do leite é a refrigeração, entretanto, soluções desse tipo nem sempre são viáveis, por razões de ordem técnica e econômica (ROSSI, 1994).

O principal conceito de qualidade é que não há como melhorá-la depois que o leite deixa a fazenda. Assim, é de suma importância melhorar as condições sanitárias nos sistemas e produção e ainda avaliar as características físico-químicas do leite que estão relacionadas com a qualidade do produto que deixa a propriedade e chega à indústria ou ao consumidor (FONSECA e SANTOS, 2000; MARTINS et al., 2007).

As maiores preocupações quanto à qualidade físico-química do leite estão associadas ao estado de conservação, à eficiência do seu tratamento térmico e integridade físico-química, principalmente aquela relacionada à adição ou remoção de substâncias químicas próprias ou estranhas à sua composição (POLEGATO; RUDGE, 2003). Segundo dados encontrados na literatura (AGNESE, 2002; DONATELE; VIEIRA; FOLLY, 2003; VIEIRA; CARVALHO, 2003), a avaliação da qualidade do leite, levando-se em conta o parâmetro acidez, por meio da determinação 
de $\mathrm{pH}$, titulação através do grau Dornic e teste de Alizarol, vem sendo bastante utilizada nos laticínios e testada por alguns pesquisadores, devido à facilidade e rapidez na sua execução.

O leite, assim como outros alimentos, é monitorado por órgãos de saúde pública utilizandose de testes específicos para determinar a qualidade dos produtos ofertados à população. O leite pode ser adulterado por diversos motivos, entre eles o econômico. Os testes físico-químicos selecionados para as análises são ferramentas para investigação de possíveis desvios em sua composição causados ou pelo mau processamento, ou intencionalmente para aumento do volume e maior lucro ou por correções de alterações na composição do leite. Substâncias estranhas, conforme tabela 1, presentes ao leite, também podem ser detectadas durante a investigação.

Tabela 1 - Substâncias estranhas adicionadas ao leite e motivo de utilização

\begin{tabular}{c|c} 
Substância & $\begin{array}{c}\text { Motivo de utilização } \\
\text { Amido } \\
\text { Sacarose } \\
\text { Cloreto de sódio } \\
\text { Bicarbonato de sódio } \\
\text { Hidróxido de sódio } \\
\text { densidade normal. } \\
\text { Peróxido de hidrogênio } \\
\text { Formol } \\
\text { Antibiótico } \\
\text { Ácido Bórico } \\
\text { Ácido salicilico }\end{array} \begin{array}{c}\text { Neutralizar o aumento da acidez do leite quando } \\
\text { em estado de deterioração. }\end{array}$ \\
$\begin{array}{c}\text { Conservar o leite, evitando a ação de } \\
\text { microorganismos. }\end{array}$ \\
\hline
\end{tabular}

De acordo com AGNESE (2002), a fraude pode ocorrer devido à adição de água ao leite, que vai alterar o seu índice de crioscopia ou mesmo a adição de qualquer outra substância que poderá também alterar outros parâmetros físico-químicos como a densidade, acidez e teor de sólidos não gordurosos.

Por outro lado, a obtenção do leite como condições higiênicas e, posteriormente, eficientes manipulação, resfriamento e transporte são fatores essenciais na manutenção da boa qualidade microbiológica e nutricional do leite “in natura” (SOUZA et al., 1995).

A presença de microrganismos no leite indica condições sanitárias inadequadas de processamento, que conduzem à deterioração e perda de qualidade, com conseqüente perigo à saúde humana caso confirme a presença de linhagens patogênicas.

Segundo PORCIONATO et al.(2008), o consumidor que desconhece os princípios básicos sobre higiene e qualidade do leite pode comprometer a própria saúde quando consome ou simplesmente manipula leite "in natura" e derivados sem tratamentos térmicos que visam diminuir a carga microbiana e principalmente eliminar microrganismos patogênicos. 
A comercialização de leite “in natura”, ou seja, sem passar por qualquer tratamento térmico, é comum na cidade de Garanhuns-PE e em outras regiões do país, devido à crença popular de que este tipo de leite seja mais rico em nutrientes e, principalmente ao baixo custo, pois ele é consumido principalmente pela população de baixa renda. Como não há garantia de que esses fatores sejam considerados pelos produtores e comerciantes, visto que não existe fiscalização sobre o produto, o presente trabalho teve como objetivo avaliar as características físico-químicas e microbiológicas “in natura” comercializado informalmente em diferentes pontos na cidade de Garanhuns - PE.

\section{Materiais e Métodos}

\subsection{Coleta de amostras}

Foram coletadas amostras de leite “in natura”, em quinze estabelecimentos comerciais, localizados em pontos distintos da cidade de Garanhuns - PE. As amostras (1000 mL) foram acondicionadas em caixa de isopor com gelo e enviadas ao Laboratório de Ensino de Química Orgânica da Universidade Federal Rural de Pernambuco/Unidade Acadêmica de Garanhuns, para análise imediata. Foram analisadas amostras, quanto aos parâmetros físico-químicos e microbiológicos, e comparadas com padrões estabelecidos pela legislação em vigor (BRASIL, 2002).

\subsection{Método de análises}

\section{Análises físico-químicas}

Os parâmetros físico-químicos avaliados foram:: acidez pela titulação de hidróxido de sódio 0,1 N com indicador fenolftaleína a $1 \%$; presença de cloretos através de iodeto de potássio a 7,5 \%; presença de peróxido de oxigênio. As determinações da densidade e $\mathrm{pH}$, bem como o teste de amido foram realizadas segundo metodologia de SILVA (2001) e LANARA (1981). As análises referentes ao teor de gordura e proteínas foram determinadas segundo metodologia proposta por FREITAS FILHO et al (2009).

\section{Análises microbiológicas}

O perfil microbiológico foi realizado através do teste da Redutase do azul de metileno (TRAM). Neste teste avalia-se a atividade das bactérias presentes no leite, por meio de um corante. Quanto mais rápido for o tempo de descoloração do corante de azul para branco, maior é o numero de micróbios existentes. No Brasil, o leite é aceito quando a descoloração ocorre a partir de duas horas e trinta minutos. 


\section{Resultados e Discussão}

As amostras foram adquiridas em pequenos supermercados da cidade de Garanhuns e em seguida analisadas obedecendo aos métodos analíticos oficiais exigidos pelo Ministério da Agricultura e de acordo com o Regulamento Técnico de Identidade e Qualidade do Leite Cru Refrigerado da IN 51 (BRASIL, 2002). Nas quinze amostras analisadas, algumas continham conservantes ou substâncias químicas, geralmente utilizadas na fraude do leite. Quanto às características principais do leite os resultados são apresentados na tabela 2 a seguir:

Tabela 2. Características físico-químicas do leite "in natura"

\begin{tabular}{cccccccc}
\hline \multirow{2}{*}{ Amostras } & \multicolumn{7}{c}{ Parâmetros físico-químicos } \\
\cline { 2 - 7 } & $\mathrm{pH}^{*}$ & $\mathrm{D}^{* *}$ & Acidez*** & Amido & Cloreto & Peróxido & Red****. \\
\hline 01 & 6,52 & 1.027 & $17{ }^{0} \mathrm{D}$ & + & + & - & $40 \mathrm{~min}$ \\
02 & 6,54 & 1.031 & $24{ }^{0} \mathrm{D}$ & + & + & - & $30 \mathrm{~min}$ \\
03 & 6,59 & 1,032 & $18{ }^{0} \mathrm{D}$ & - & - & + & $50 \mathrm{~min}$ \\
04 & 6,13 & 1,032 & $12{ }^{0} \mathrm{D}$ & - & - & - & $+2,5 \mathrm{hs}$ \\
05 & 6,25 & 1,029 & $12{ }^{0} \mathrm{D}$ & - & - & - & $+2,5 \mathrm{hs}$ \\
06 & 6,64 & 1,028 & $16{ }^{0} \mathrm{D}$ & - & - & - & $+2,5 \mathrm{hs}$ \\
07 & 6,77 & 1,027 & $18{ }^{0} \mathrm{D}$ & - & - & + & $+2,5 \mathrm{hs}$ \\
08 & 6,57 & 1,031 & $19{ }^{0} \mathrm{D}$ & - & - & - & $+2,5 \mathrm{hs}$ \\
09 & 6,74 & 1,028 & $16{ }^{0} \mathrm{D}$ & - & - & - & $+2,5 \mathrm{hs}$ \\
10 & 6,20 & 1,030 & $13{ }^{0} \mathrm{D}$ & - & - & - & $30 \mathrm{~min}$ \\
11 & 6,77 & 1,031 & $18{ }^{0} \mathrm{D}$ & - & - & + & $+2,5 \mathrm{hs}$ \\
12 & 6,57 & 1,010 & $15{ }^{0} \mathrm{D}$ & - & - & - & $+2,5 \mathrm{hs}$ \\
13 & 6,62 & 1,050 & $13{ }^{0} \mathrm{D}$ & + & - & - & $+2,5 \mathrm{hs}$ \\
14 & 6,67 & 1,031 & $16{ }^{0} \mathrm{D}$ & - & - & - & $+2,5 \mathrm{hs}$ \\
15 & 6,63 & 1,010 & $18{ }^{0} \mathrm{D}$ & - & - & - & $+2,5 \mathrm{hs}$ \\
\hline \multicolumn{7}{c}{$* 20{ }^{0} \mathrm{C}$} \\
\end{tabular}

De acordo com dados da tabela 2, os valores de $\mathrm{pH}$ para as amostras 01, 02, 03, 06, 07 , 08,09,11,12,13,14 e 15 estão dentro da faixa ideal, ou seja, os valores de $\mathrm{pH}$ do leite normal ficam entre 6,43 a 6,82 e é um indicador da qualidade sanitária e da estabilidade térmica do leite. Nos casos graves de mastite, o pH pode chegar a 7,5 e na presença de colostro, pode cair a 6,0.

A densidade do leite deve apresentar-se entre 1,028 e 1,034, segundo recomendação da legislação vigente (BRASIL, 2002). Valores abaixo dessa faixa podem indicar adição de água, e valores acima, fraude por adição de outras substâncias ou desnate do leite (POLEGATO; RUDGE, 2003). Logo, de acordo com dados expressos na tabela 2, as amostras 01, 07, 12 e 15 apresentam valores inferiores preconizados pela legislação, provavelmente devido à fraude por adição de água detectada nas mesmas. A amostra 13 possui densidade acima do valor previsto na legislação vigente. Acredita-se que o valor acima se deva a fraude por adição de outras substâncias ou desnate do leite. Vale destacar que a foi detectado nesta amostra a presença de sacarose e amido. As demais amostras estão dentro do intervalo aceitável. 
Em relação à acidez as amostras 01, 03, 06, 07, 09, 11, 12, 14 e 15 (60\%) apresentaram-se dentro de padrões, quatro (26,7\%) apresentaram valores inferiores ao mínimo aceitáveis e duas (13,3\%) acima do máximo exigido. O parâmetro acidez foi avaliado por meio de titulação através de graus Dornic os quais ainda são bastante utilizados pelas mini usinas de laticínios, principalmente devido à facilidade e rapidez na sua execução. Os resultados obtidos para acidez indicam que provavelmente houve falta de higienização durante a obtenção do leite. Segundo OLIVEIRA, NUNES e ABREU (2003), a acidez elevada no leite pode ser resultado da acidificação da lactose, provocada pela multiplicação de microrganismos deterioradores e/ou patogênicos.

A pesquisa de fraude no leite foi realizada visando identificar a presença de conservadores e de substâncias químicas mais comuns adicionadas ao leite. Nas amostras 01, 02 e 13 foi constado a presença de amido, segundo BEHMER (1984), amido, açúcar e urina são utilizados criminosamente para encobrir a molhagem do leite.

Nas amostras 01 e 02 foram detectadas a presença do conservante cloro e nas amostras 03, 07 e 10 água oxigenada. Estes conservantes já haviam sido detectados por FREITAS et al. (1995) que, em Belém, em 10\% das amostras de leite cru havia inibidor bacteriano na forma de água oxigenada.

$\mathrm{Na}$ avaliação feita pelo teste de redutase, verificou-se que as amostras 01, 02, 03 e 10 (26,7\%) apresentaram péssima qualidade microbiológica. Diversos fatores, entre os quais conservação, demanda, temperatura, estação do ano, condições de produção e sistemas de comercialização afetam as características do leite.

No trabalho também foi determinado o teor de gordura e proteínas, os quais estão sumarizados na tabela 4.

Tabela 4. Teor de proteína e gordura no leite " in natura”

\begin{tabular}{ccc}
\hline & \multicolumn{2}{c}{ Parâmetros físico-químicos } \\
\cline { 2 - 3 } AMOSTRAS & Proteínas & Gorduras \\
\cline { 2 - 3 } 01 & $3,14 \%$ & $1,87 \%$ \\
02 & $2,21 \%$ & $2,51 \%$ \\
03 & $2,97 \%$ & $2,80 \%$ \\
04 & $1,97 \%$ & $1,46 \%$ \\
05 & $1,85 \%$ & $1,13 \%$ \\
06 & $4,42 \%$ & $2,40 \%$ \\
07 & $3,49 \%$ & $3,50 \%$ \\
08 & $2,21 \%$ & $2,65 \%$ \\
09 & $3,75 \%$ & $5,75 \%$ \\
10 & $1,76 \%$ & $1.25 \%$ \\
11 & $2,52 \%$ & $2,45 \%$ \\
12 & $3,86 \%$ & $2.95 \%$ \\
13 & $1,85 \%$ & $1,53 \%$ \\
14 & $3,96 \%$ & $2,75 \%$ \\
15 & $3,02 \%$ & $2,63 \%$ \\
\hline
\end{tabular}

De acordo com resultados expressos na tabela 4, observa-se que o teor de proteína variou de 
4,42 a 1,76\% e o teor de gordura analisadas nas amostras variou de 1,13 a 3,50. Logo observou a redução nos teores de proteína e gordura no leite analisados.

\section{Conclusões}

Nas condições em que o trabalho foi realizado pode-se concluir que algumas das amostras de leite “in natura” apresentaram valores aceitáveis para todos os parâmetros analisados.

Uma acidez acima de $18^{\circ}$ Dornic é proveniente da acidificacao do leite, causada pelo desdobramento da lactose provocada por bacterias que se encontram em intensa multiplicação no leite.

Os valores de pH e acidez do leite não são proporcionais, embora haja uma relação inversa, ou seja, a medida que a acidez se eleva, ocorre abaixamento do $\mathrm{pH}$.

Dentre as características físico-químicas avaliadas, verificou-se que a falta de padronização do teor de gordura e a fraude em relação à adição de água no leite foram alguns dos principais problemas encontrados.

Foram detectadas algumas irregularidades nos aspectos físico-químicos e microbiológico de $40 \%$ da amostras analisadas. Portanto, torna-se evidente a necessidade de adoção de medidas que visem melhorar a qualidade do leite "in natura” comercializado informalmente na cidade de Garanhuns - PE.

\section{Agradecimentos}

Os autores do trabalho agradecem a FACEPE pelo suporte financeiro.

\section{Abstract}

The objective of this study was to evaluate the physical-chemical and microbiological characteristic of milk "in natura" marketed in the city of the Garanhuns - PE. Samples were collected in small supermarkets of Garanhun- PE from february to July of 2009. The average values of density were below and above the recommended limits, respectively. For acidity, some samples had to be within the standards required and $25 \%$ had values below the minimum required, and and two samples $(28,57 \%)$ were of bad quality microbiological, according to tests reductase. Preservatives for the presence of chlorine and hydrogen peroxide, 25\% and 14\% respectively, of the samples showed positive results.

Key-words: Milk “in natura”, physical-chemical parameters, microbiological.

\section{Referências}

AGNESE, A. P. Avaliação físico-química do leite cru comercializado informalmente no município de Seropédica, Rio de Janeiro. Revista Higiene Alimentar, São Paulo, v. 17, n. 94, p. 58-61, 2002.

BEHMER, M.l. L. A. Tecnologia do leite: leite, queijo, manteiga, caseína, iogurte, sorvetes e instalações: produção, industrialização, analise. $13^{\circ} \mathrm{ed}$. São Paulo: Nobel, 1984. 
BRASIL. Ministério da Agricultura, Pecuária e Abastecimento. Instrução Normativa no. 051, de 18de setembro de 2002. Diário Oficial da União, Brasília, 20 set., Seção 1, p. 13-22. 2002.

DONATELE, D. M.; VIEIRA, L. F. P.; FOLLY, M. M. Relação do teste de Alizarol 72\% (v/) em leite “in natura” de vaca com acidez e contagem de células somáticas: Análise Microbiológica, Revista Higiene Alimentar, São Paulo, v. 17, n. 110, p. 95-100, 2003.

FONSECA, L. F. L.; SANTOS, M. V. Qualidade do leite e controle de mastite. São Paulo: Lemos, 2000.

FREITAS, J. A., SILVA, R. A. G., NASCIMENTO, J. A. C. Características do leite fluido consumido em Belém, Pará. Arquivo Brasileiro de Medicina Veterinária e Zootecnia. v. 47, n. 3, p. 435- 445, 1995.

FREITAS FILHO, J. R; FREITAS, W. R.; LIMA, R. S.; SILVA, M. S. J.; LIMA,R. T.; SOUZA, H. B.; LIMA, V. A. M. Avaliação do teor de caseína e albumina no leite de vacas da raça Girolanda. Revista Brasileira de Tecnologia Agroindustrial. Vol.3, No. 1, 2009.

LANARA. Métodos analíticos oficias para Controle de Origem Animal e seus Ingredientes - II - Métodos Físicos e Químicos. 1981.

LEITE JR, A. F. S.; TORRANO, A. D. M.; GELLI, D. S. Qualidade microbiológica do leite tipo C pasteurizado, comercializado em João Pessoa, Paraíba. Revista Higiene Alimentar, São Paulo, v. 14, n. 74, p. 45-49, 2000.

LISBOA, J. C. F.; BOSSOLANI, M. Tipos de Leite, Substâncias Estranhas e Obtenção de Plástico, QUÍMICA NOVA NA ESCOLA - Experiências Lácteas Nº 6, 1997.

MARTINS, P. R. G. et al. Produção e qualidade do leite em sistemas de produção da região leiteira de Pelotas, RS, Brasil. Ciência Rural, v. 37, n. 1, p. 212-217, 2007.

MENDONÇA, A.H. et al. Qualidade físico-química de leite cru resfriado: comparação de diferentes procedimentos e locais de coleta. In: CONGRESSO NACIONAL DE LATICÍNIOS, 18., 2001, Juiz de Fora. Anais... Juiz de Fora: Templo. 2001. p.276-282.

OLIVEIRA, M.M.A.O.; NUNES, I.F.S.N.; ABREU, M.C. Análise microbiológica e físico-química do leite pasteurizado tipo C comercializado em Terezina, PI. Higiene Alimentar, São Paulo, v. 17, n. 111, p. 92-94, agosto, 2003.

PORCIONATO, M. A. F.; REIS, C. B. M. dos; BARREIRO, J. R.; MORENO, J. F. G.; MESTIERI, L. Rev. Acad., Ciênc. Agrár. Ambient., Curitiba, v. 6, n. 4, p. 511-517, 2008.

POLEGATO, E. P. S.; RUDGE, A. C. Estudo das características físico-químicas e microbiológicas dos leites produzidos por mini-usinas da região de Marília - São Paulo/ Brasil. Revista Higiene Alimentar, São Paulo, v. 17, n. 110, p. 56-63, 2003.

ROSSI, E.A.. O sistema lactoperoxidase na preservação de leite cru nas condições brasileiras. Dissertação de Doutorado. Campinas, Unicamp, 1992.126p.

ROSSI, E.A.; OLIVEIRA, J.S.; FARIA, J.B.. Efeito da concentração de água oxigenada na eficiência do sistema lactoperoxidase ativado em leite. Ciência e Tecn. de Alimentos, Campinas, 14(2):178-88, 1994.

SÁ, E. Análises realizadas para o controle da qualidade de leite in natura de acordo com os parâmetros legais. Revista Leite \& Derivados, ano XIV, n. 81, p. 67-72. 2004.

SILVA, P. H. F. da. Físico-química do leite e derivados: métodos analíticos. Juiz de Fora, 1997.

SOUZA, M. R., RODRIGUES, R., FONSECA, L. M., CERQEUIRA, M. M. O. P. Pasteurização do leite. Caderno Técnico da Escola de Veterinária UFMG, n. 13, p.85-93, 1995

F. G.; MESTIERI, L. Rev. Acad., Ciênc. Agrár. Ambient., Curitiba, v. 6, n. 4, p. 511-517, 2008.

TEIXEIRA, S.R. Pagamento pela Qualidade. In: BRITO, J.R.F.; DIAS, J.C. A Qualidade do Leite. EMBRAPA/TORTUGA,. p.51-58, 1998.

TIMM, C. D. Avaliação da qualidade microbiológica do leite pasteurizado integral, produzido em micro-usinas da região sul do Rio Grande do Sul. Revista Higiene Alimentar, São Paulo, v. 17, n. 106, p. 100-104, 2003. 
VIEIRA, T. R. L.; CARVALHO, M. G. X. Características microbiológicas e físico-químicas e condições higiênicosanitárias do leite pasteurizado tipo "C" comercializados na cidade de Patos - PB. In: CONGRESSO NACIONAL DE LATICÍNIOS, 20, 2003, Juiz de Fora. Anais... Juiz de Fora: Central Formulários, v. 58, n. 333, p. 201-203, 2003.

Nome completo: João Rufino de Freitas Filho

Filiação institucional: Universidade Federal Rural de Pernambuco

Departamento: Unidade Acadêmica de Garanhuns

Função ou cargo ocupado: Professor Adjunto I

Endereço completo para correspondência (bairro, cidade, estado, país e CEP): Av. Dr.Jardim, Aluísio Pinto, Garanhuns, Pernambuco, Brasil, CEP: 55292-060

Telefones para contato: (87)3762-0438, (87)99995855

e-mail: joaoveronice@yahoo.com.br 